\title{
FIRE PERFORMANCE OF COMPOSITE-PANEL SEPARATION WALLS
}

\author{
Miroslav Smolka $^{\mathrm{a}}$, Vladimír Mózer ${ }^{\mathrm{a}}$, Piotr Tofiło $^{\mathrm{b}}$ \\ ${ }^{a}$ University of Zilina, Faculty of Security Engineering, ul. 1. maja 32, 01026 Zilina, Slovak Republic \\ ${ }^{b}$ Main School of Fire Service, Juliusza Słowackiego 52/54, Warszaw 01-629, Poland
}

\begin{abstract}
Composite panel walls with both combustible and non-combustible cores were subjected to fire resistance test to EN 1364-1. The results revealed that the combustible-core panels started emitting smoke on the unexposed side due to the presence of joints between panels. In some cases the smoke emission started early after the start for the fire exposure. The start of the smoke production period appeared to depend on the fixation of the panels to the furnace frame; three or four sides fixed as per EN 1364-1. The amounts of smoke released indicate that although smoke leakage/production criterion is not currently part of the standard fire-resistance testing protocol it should be assessed when construction elements with combustible components are tested. Otherwise such a barrier may not be considered as a smoke-safe separating element, because model FED calculations indicate a potential threat to the occupants on the unexposed side at a certain set of conditions.
\end{abstract}

Keywords: fire resistance, sandwich panels, free edge, smoke emission, fire compartmentation

\section{INTRODUCTION}

The purpose of fire resistance testing is to verify the fitness of fire separating barriers (typically walls and floors) for use as boundaries of fire compartments. Based on the definition of compartmentation - The subdivision of a building into relatively small areas so that fire or smoke can be confined to the room or section in which it originates (Code NFPA 232) - the assumption is that the fire barrier itself is not a contributing element to fire and smoke spread to the safe side.

The tests simulate post-flashover fire conditions using the standard temperature/time curve, as expressed by the European standard fire resistance testing, according to EN 1363-1. Nonloadbearing walls are tested to EN 1364-1. None of these tests are intended to evaluate or quantify smoke emission from the tested boundaries of fire compartments (Fig. 1).

\section{FIRE RESISTANCE TESTS WITH ADDITIONAL SMOKE MEASUREMENTS}

Two series of experimental fire resistance tests have been carried out to EN 1364-1. Sandwich panels with steel facings and the cores made of non-combustible insulation (mineral wool - MW) and combustible insulation (polyisocyanurate - PIR) were chosen as examples of non-loadbearing walls. Both types are commonly used as part of a fire resistant building envelope and as fire separating walls within buildings, subjected to CE-marking to EN 14509. Two or three identical specimens of each type of product tested using particular installation method were used for the test. In addition to standard measurements and observations, the following phenomena and values were measured and/or observed:

- Observation of smoke emissions from the safe (unexposed) side of the walls tested.

- Estimate of heat released from the fire (exposed) side of the walls tested, using the actual amount of fuel burned in the test furnace to achieve the EN 1363-1 standard time/temperature curve compared to an inert non-combustible aerated concrete wall.

- Measurement of opacity of smoke and particle distribution emitted to the safe side of the walls tested.

- Quantative and qualitative measurements of smoke emitted to the safe side of the walls tested, subsequently analysed for its composition and toxic effects on humans. 
Results of both series of tests, overview and discussion of results have been published by Smolka et al. in 2013 and 2015. Complete set of results and analysis of smoke emission measurements in fire resistance tests and in small scale using ISO/TR 19700 has been published in the SP Report 2014:25 (Blomqvist et al., 2014).

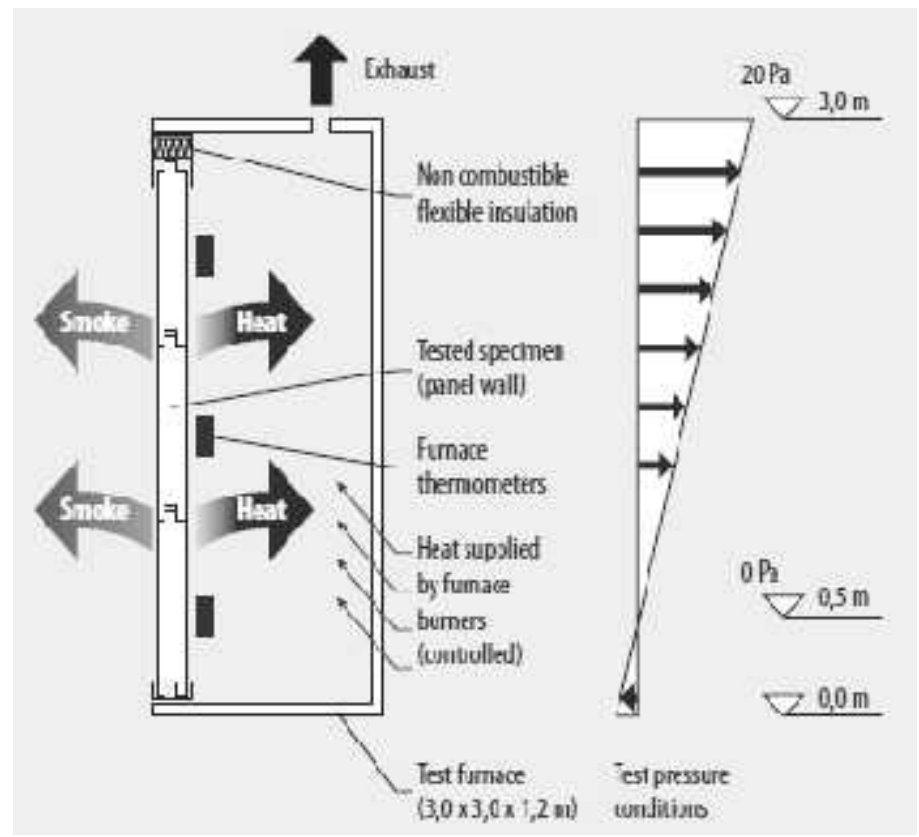

Fig. 1 When a segment of a fire separating structure is tested for fire resistance, its contribution to heat and smoke development to either side is not part of the measurements or observations.

\section{TESTED PRODUCTS AND INSTALLATION METHODS}

Apart from showing a distinct difference in the above mentioned fire performance measurements and observations, between the combustible-cored and the non-combustible cored sandwich panel walls, differences in behaviour between identical specimens were observed. These apparently resulted from different methods chosen for installation of the tested walls in the two test series.

\subsection{Panel walls fixed on three sides with a free vertical edge}

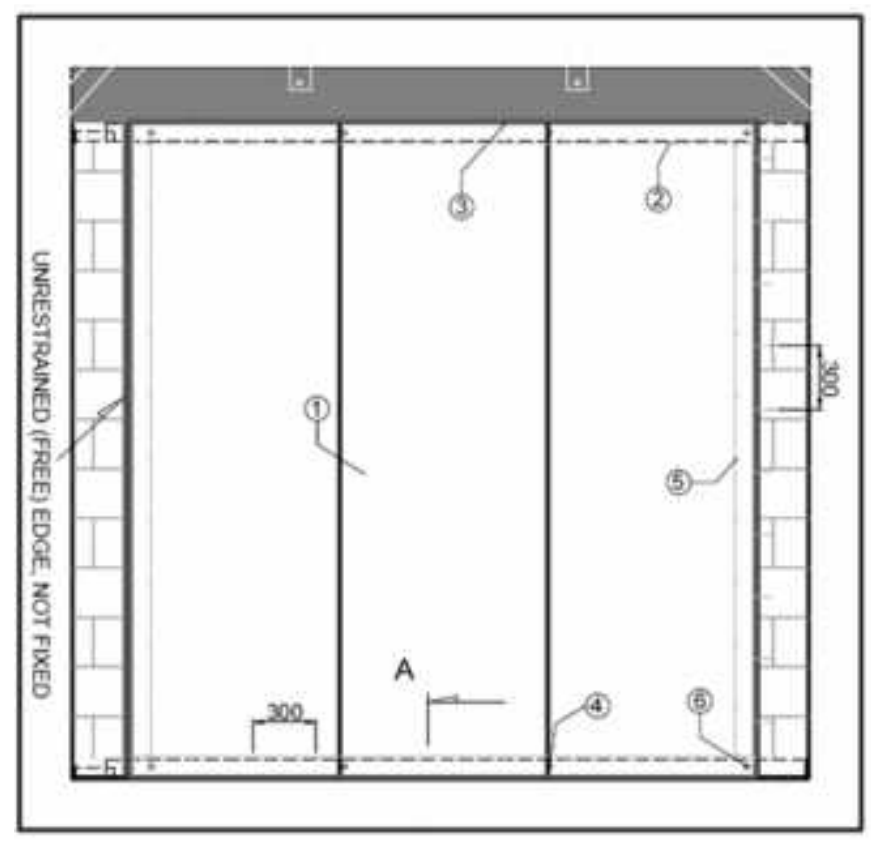

Fig. 2 Standard mounting of a non-loadbearing wall tested for fire resistance, with a vertical free edge (simulation of a situation that the wall installed in practice will be wider than the $3 \mathrm{~m}$ tested width) 
In the first part of the project, the panels were fixed to hot-rolled steel beams using the screws specified by the producers, in full accordance with the test method EN 1364-1 (Fig. 2). The fixing method used in these tests was chosen to be representative of practice where panels are mounted on a load-bearing steel structure of a building. Two parallel U-shaped hot-rolled steel profiles were used to simulate the load-bearing building structure. These profiles were welded on one side, and laid in brackets to allow for thermal expansion on the other side (Fig 3).

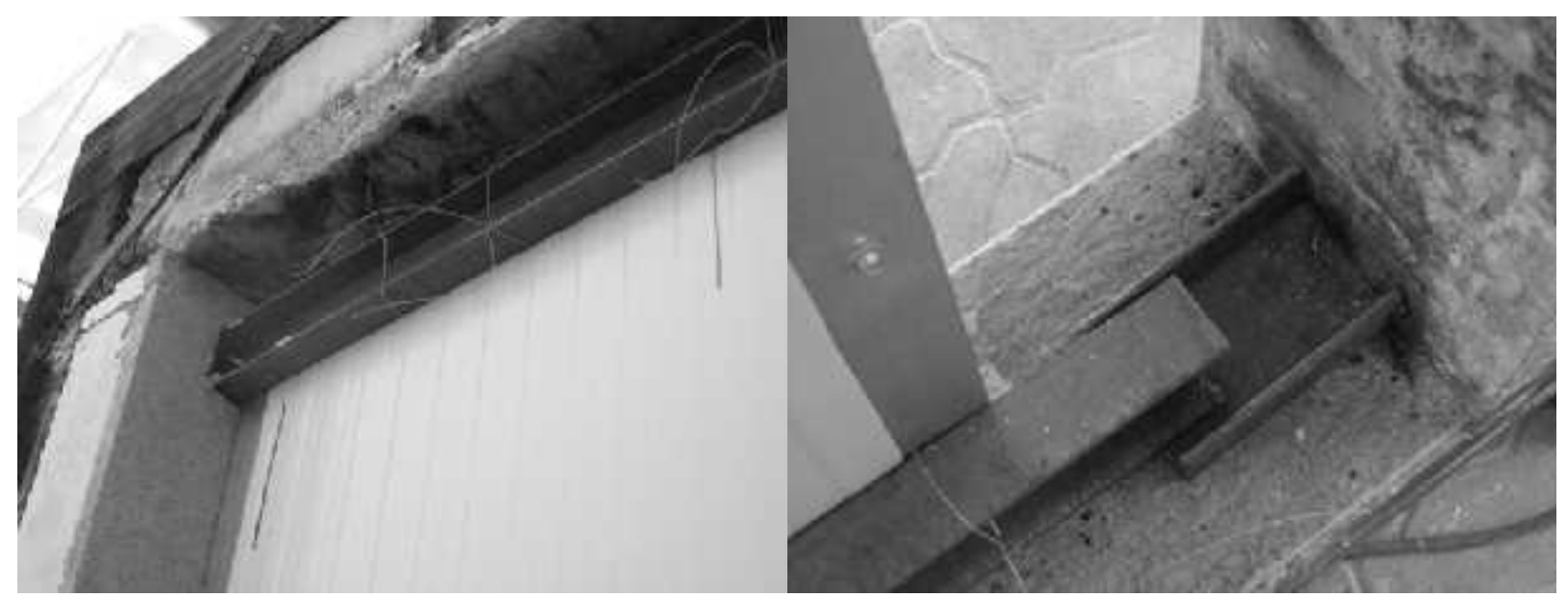

Fig. 3 The load-bearing steel structure was allowed to expand during the fire resistance test (simulation of a situation that the wall installed in practice will be wider than the $3 \mathrm{~m}$ tested width)

The panels were attached to a fire-protected steel profile as shown in Fig 4.

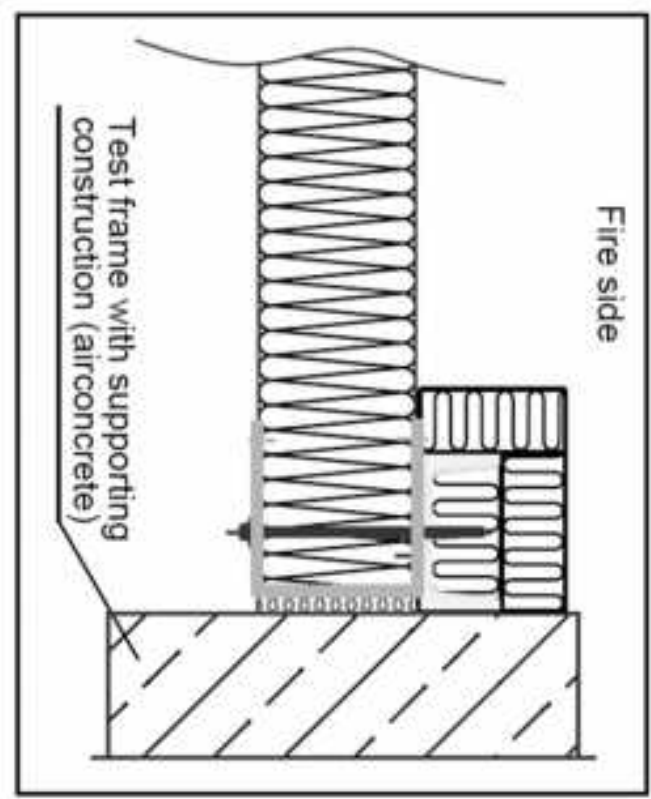
(1) - wall panel
(2) - steel sheet flashing (to embedd specimen edges)
(3)- steel loacbearing U-profile
(4). self drilling screw EJOT JT2-D-12H-5,5/6,3×95 V16 (fixing of panels to the steel badbearing profiles
(5)- self drilting stitching screw $\emptyset(4,8 \times 19) \mathrm{mm}$. fixing of perimeter flashing to panels
(B)- self driling screw EJOT JT2-D-12H-5,5/6,3×135 V16 (fixing of panels to the steel loadbearing profiles

Fig. 4 Panels attached to hot-rolled steel U-profiles simulating the load-bearing building structure 


\subsection{Panel walls fixed on all four sides}

During the second set of fire resistance experimental walls, the panels were attached to a thin Lshaped steel profiles placed around the perimeter of the walls. No free edge joint was used here to achieve a maximum tightness possible between the furnace and the external environment. This way of mounting and fixing is not typical for fire resistance testing of non-loadbearing walls, but allowed by the test method. The fixation of the panels to the furnace frame is shown in Fig. 5 .

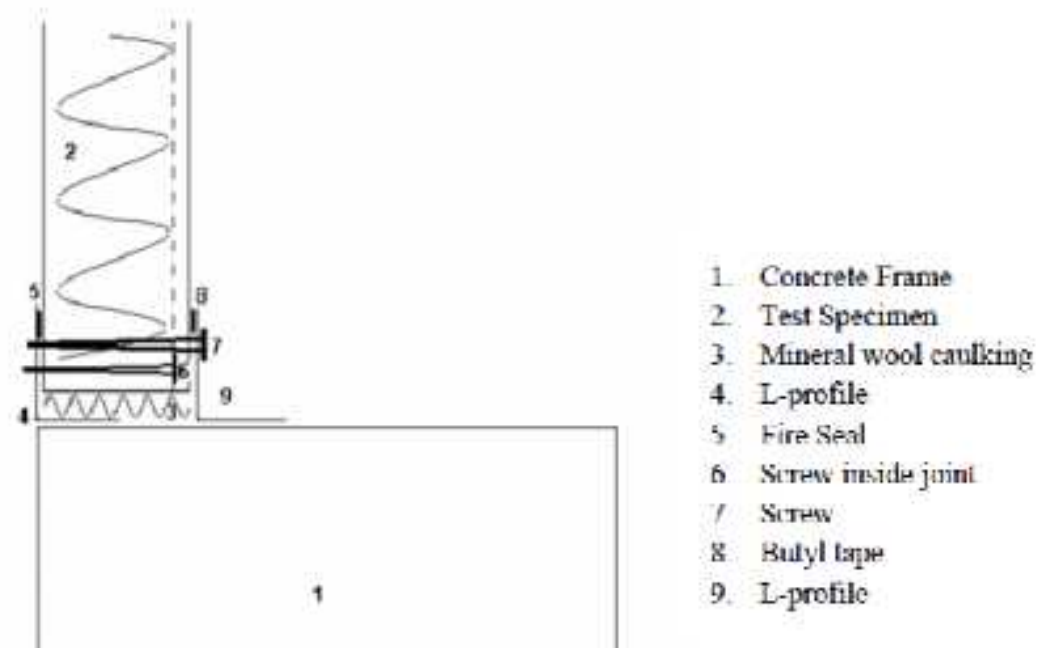

Fig. 5 Panels attached to cold-rolled steel L-profiles mounted within the concrete test furnace frame simulating the adjacent concrete floor, ceiling, and walls

\section{RESULTS: IMPACT OF INSTALLATION ON SMOKE AND HEAT EMISSION}

\subsection{Panel walls fixed on three sides with a free vertical edge}

When the free-edge installation was used and the panel walls were attached on three edges only, the behaviour of the tested elements showed that:

- Two of the four PIR-cored panels displayed heavy smoke emission on the safe (unexposed) side, changing over time erratically.

- Heat released from the specimens differed; the difference not only being between MW-cored and PIR-cored panel walls, but also among the PIR-cored panel walls themselves.

- Heat input from the burners seemed inversely proportional to smoke emissions on the unexposed side outside the furnace, comparing different test specimens, as well as comparing different test periods of individual test specimens.

- The first joint that opened and started to emit visible smoke was the one closer to the free edge, in all the tests conducted in this series, as shown in Fig. 6. It was apparently due to different strain generated inside the tested wall on the joints, resulting from the from heat expansion of the steel facings. 

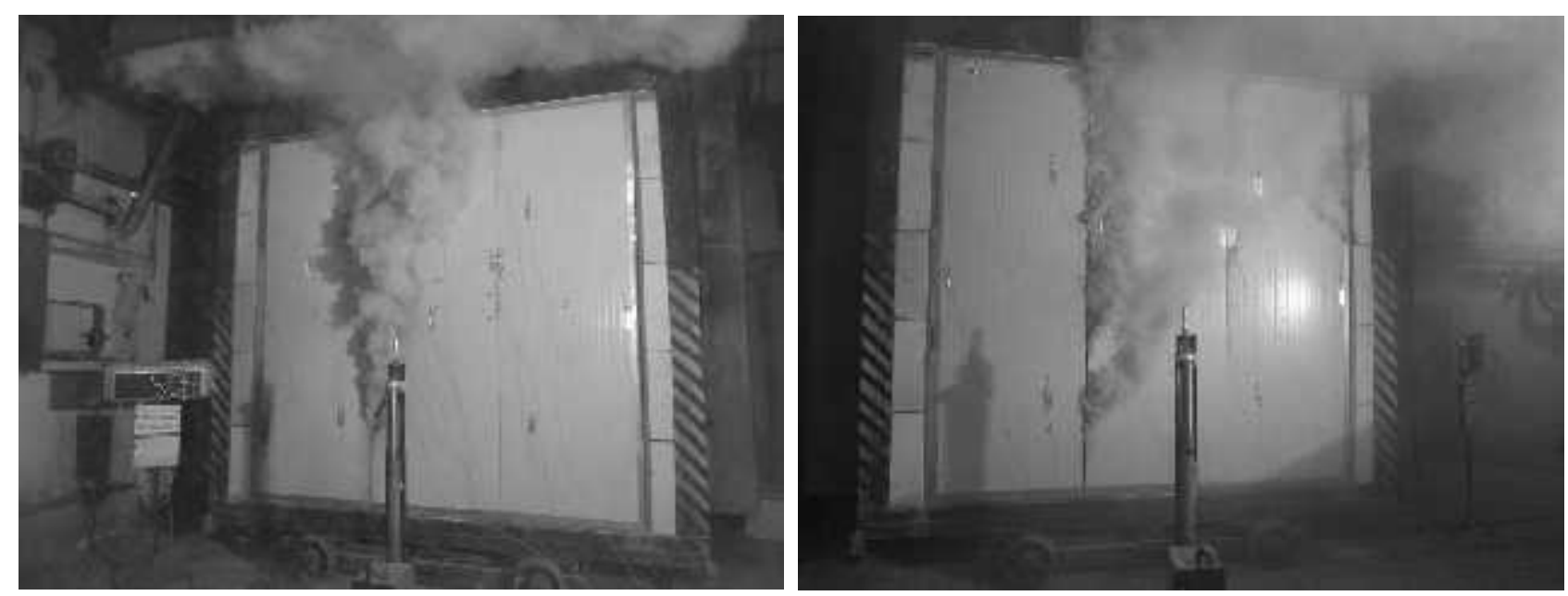

Fig. 6 Panel wall with a free vertical edge: joint placed closer to the free edge was the first to start releasing smoke in all the tests carried out

In this first series of tests, no smoke capture or analysis was carried out.

\subsection{Panel walls fixed on all four sides}

When the free edge was not used and the panel walls were attached on all four sides, the behaviour of the tested elements showed that all three PIR-cored tested walls displayed remarkably similar smoke emission patterns, with heavy smoke emission starting about 10 minutes and continuing onwards into the tests. Contributions of PIR-core panel walls to heat emission were uniform throughout the test as well as among the tested specimens.

The three tests conducted has not shown any pattern as to which of the two joints would emit smoke first, as shown in Fig. 7. This was apparently due to the symmetrical fixation of panel walls.
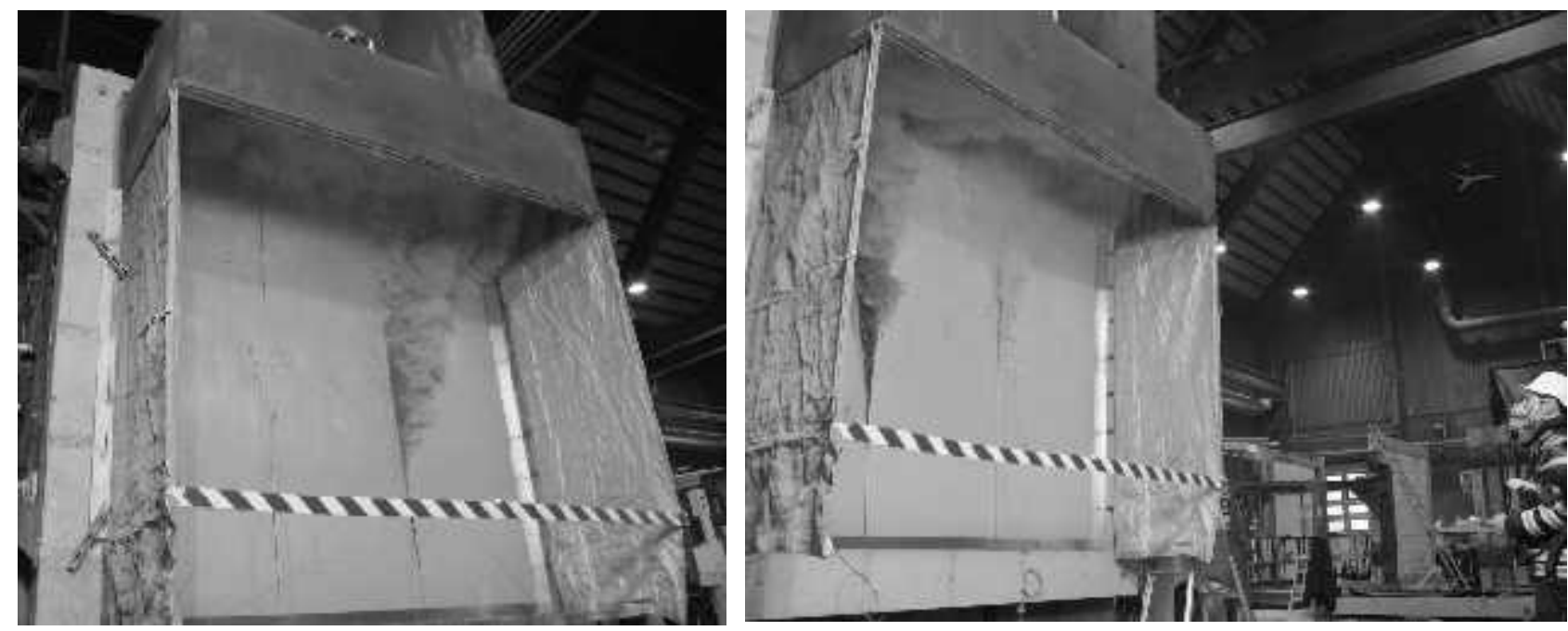

Fig. 7 Panel wall without a free vertical edge: any of the two panel joints (or both) could be seen to release visible smoke; no pattern was observed as to which of the joints will start emitting smoke first

During the second series of tests when all the smoke emitted from the safe side was captured and analysed, it became apparent that the visible smoke emissions from combustible-core panel walls correlated well with the measured concentrations of major combustion gases: $\mathrm{CO}_{2}, \mathrm{CO}$, and $\mathrm{HCN}$. Out of the three combustion species, $\mathrm{HCN}$ was found the most significant contributor to overall toxicity (Blomqvist et al., 2014).

\section{CONCLUSIONS}

The first series of fire resistance tests made on sandwich panel walls have shown that metal faced sandwich panels with combustible core do not make inert boundaries of fire compartments. When 
exposed to a fully developed fire form one side, these structures are capable of releasing substantial amounts of smoke to the safe side, or heat to the fire side. These phenomena appear inversely related.

The second series of fire resistance tests equipped with unexposed side smoke capture and analysis have shown that visible smoke emissions are accompanied by increased concentrations of major toxic species: $\mathrm{HCN}, \mathrm{CO}$, and $\mathrm{CO}_{2}$.

Apart from these confirming results, two distinct emission patterns were observed: erratic smoke emission in the first series and a much more uniform emission pattern in the second series of tests. These appear to be dependent on the two different installation methods used.

Required by EN 1364-1, the free edge simulates the wall which is much wider than the standard $3 \mathrm{~m}$ $\mathrm{x} 3 \mathrm{~m}$ tested size; when used, the wall width can be unlimited in practice. The free edge was used in the first series of tests, which resulted in different mechanical strain induced within the wall from thermal expansion, and significant smoke emissions from the panel joint placed closer to the free edge.

The second series of tests did not used the free edge, which resulted in symmetrical induced stress on both panel joints, and uniform smoke emissions similar in all the three tested wall specimens.

The project has shown that fire resistance tests equipped with smoke capture and instrumentation are capable of quantifying smoke emission in terms of particle distribution, opacity and toxicity. The values obtained can be subsequently used for modelling of real building situations. However, the goal to obtain quality data should not contradict basic requirements of test specimen installation, with potential impact on end use of the tested element of building structure.

\section{REFERENCES}

CODE NFPA 232. Standard for the Protection of Records (2000 Edition).

EN 1363-1 Fire resistance tests. Part 1: General requirements. CEN.

EN 1364-1 Fire resistance tests for non-loadbearing elements. Part 1: Walls. CEN.

EN 14509 Self-supporting double skin metal faced insulating panels - Factory made products Specifications. CEN.

Blomqvist P., Johansson P., Comparison of fire effluent composition between large-scale and small-scale tests with sandwich panels. SP report 2014:25

Smolka, M., Mozer, V., Tofilo, P., 2015. Gas and particle effluents released from boundaries of fire compartments: First results and analyses, in Proceedings from the Fire and Materials 2015 Conference, London: Interscience Communications, February 2015.

Smolka, M., Suurenbroek Y., 2013. Smoke and heat emissions as the measures of interaction of tested elements with test environment in fire resistance testing, in Interflam conference proceedings, London: Interscience Communications, June 2013. 